\title{
Ischemic arterial events and atherosclerosis in patients with systemic sclerosis: a population- based case-control study
}

\author{
Annica Nordin ${ }^{1 *}$, Kerstin Jensen-Urstad ${ }^{2}$, Lena Björnådal ${ }^{1}$, Susanne Pettersson ${ }^{3,1}$, Anders Larsson $^{4}$ and \\ Elisabet Svenungsson ${ }^{1}$
}

\begin{abstract}
Introduction: While microvascular disease is well described in systemic sclerosis (SSc), it is still unclear whether the occurrence of ischemic macrovascular events and atherosclerosis is enhanced among patients with SSc.

Methods: In this study, 111 SSc patients (74\% of prevalent cases in Stockholm County) and 105 age- and sexcomparable population controls were investigated. Previous ischemic arterial events were tabulated. As surrogate measures of atherosclerosis, plaque occurrence and intima-media thickness (IMT) were determined with carotid ultrasound and the ankle-brachial index (ABI) was calculated. Traditional cardiovascular risk factors were recorded and we also measured biomarkers indicating systemic inflammation and endothelial activation/dysfunction.

Results: Mean age was $62 \pm 12$ years for patients and controls. Ischemic arterial events were more common, due to increased occurrence of ischemic heart disease (IHD) and ischemic peripheral vascular disease (IPVD), in the patient group ( $12 \%$ vs. $4 \%, P=0.03$ and $9 \%$ vs. $0 \%, P=0.003$ respectively). On a group level, there was no difference regarding the occurrence of ischemic cerebrovascular disease, the frequency of plaques, IMT or ABI between SSC patients and controls. Subgroup analyses revealed that patients with anticentromere antibodies (ACA +) had more plaques and more ischemic arterial events compared to other SSC patients (67\% vs. 39\% and 32\% vs. $11 \% ; P=0.006$ and $P=0.01$, respectively) and compared to controls $(67 \%$ vs. $41 \%$ and $32 \%$ vs. $7 \%, P=0.02$ and $P$ $=0.0003$, respectively). Biomarkers of inflammation/endothelial activation were generally increased among SSC patients.

Conclusions: Patients with SSC are at enhanced risk for IHD and IPVD. The ACA+ SSC subgroup was particularly affected with both ischemic arterial events and premature atherosclerosis. The microvascular vulnerability of ACA+ patients is previously well documented. We demonstrate that ACA+ SSC patients have an enhanced risk of macrovascular injury as well. This group should be followed closely and modifiable cardiovascular risk factors should be treated at an early stage.
\end{abstract}

\section{Introduction}

Systemic sclerosis (SSc) is an autoimmune rheumatic disease characterized by fibrosis of the skin, microvasculopathy and involvement of internal organs. Patients with SSc have a shortened lifespan mainly due to heart and lung manifestations [1]. In other autoimmune diseases such as systemic lupus erythematosus (SLE) and

\footnotetext{
* Correspondence: annika.nordin@karolinska.se

'Rheumatology Unit, Department of Medicine, Karolinska University Hospital,

Solna, Karolinska Institutet, SE-171 76 Stockholm, Sweden

Full list of author information is available at the end of the article
}

rheumatoid arthritis (RA) the occurrence of premature cardiovascular morbidity and subclinical atherosclerosis has been well documented $[2,3]$. Whether ischemic macrovascular disease and/or accelerated atherosclerosis also are features of SSc is unclear. Most previous studies are fairly small and results contradictive [4-6], however, a recent meta-analysis concluded that carotid intimamedia thickness (IMT) was greater in SSc patients than in controls [7].

The pathogenesis of SSc is unknown, but activation of $\mathrm{B}$ cells results in the production of antinuclear antibodies
Ciomed Central

() 2013 Nordin et al.; licensee BioMed Central Ltd. This is an open access article distributed under the terms of the Creative Commons Attribution License (http://creativecommons.org/licenses/by/2.0), which permits unrestricted use, distribution, and reproduction in any medium, provided the original work is properly cited. 
(ANA) in $90 \%$ of patients. The ANA specificities most commonly demonstrated in SSc; anticentromere (ACA) and antitopoisomerase 1 (ATA) antibodies, characterize two different clinical SSc subsets. In limited cutaneous scleroderma (lcSSc, $80 \%$ of SSc) the occurrence of ACA is common [8] and Raynaud's phenomena may precede fibrotic skin by several years [1]. Diffuse cutaneous systemic sclerosis (dcSSc) is less common, associated with ATA, and an extensive skin involvement and pulmonary fibrosis often parallel or may even precede Raynaud's phenomena.

In this study, we investigated the prevalence of ischemic arterial events and measures of atherosclerosis in patients with SSc and in controls from the general population. Traditional cardiovascular risk factors were tabulated. Since both atherosclerosis and cardiovascular disease are known to be associated with systemic inflammation, we also investigated the distribution of a large set of inflammatory and endothelial biomarkers.

\section{Methods}

\section{Patients and controls}

All participants were $>18$ years old and recruited from the adult population in Stockholm County $(N=1,534,272)$ between August 2006 and December 2009. Prevalent cases with SSc were identified at the three Rheumatology clinics associated with general/university hospitals and from all rheumatologists with private practice. All dermatologists, gastroenterologists, specialists in respiratory medicine, hand surgeons and general practitioners were contacted twice and asked to inform us about their patients with SSc. We identified 149 cases fulfilling the American College of Rheumatology (ACR) criteria for SSc [9], which corresponds to a prevalence of 97 adult SSc cases/million. A total of $74 \%$ participated in the study. According to our review of medical records, the remaining $26 \%$ did not differ from the included patients regarding age, disease duration or severe organ manifestations. Control subjects were recruited from the same population through use of the national registration number, which includes date of birth and is coded for sex. The sex-matched person with the birth date closest to the patient was contacted and asked to participate. Some $65 \%$ of these 'first choice' controls accepted to participate. When the 'first choice' declined, the second-closest person was asked, until a control subject gave his/her consent. A diagnosis of SSc was the only exclusion criteria. A total of 105 controls were included.

The local ethics committee of the Karolinska University Hospital approved the study and all participants gave written informed consent.

\section{Study protocol}

All participants underwent a structured interview and a physical examination by a rheumatologist (AN, LB).
The patients were classified as lcSSc or dcSSc using the LeRoy classification [10]. Skin score was measured with the modified Rodnan skin score [11] and disease activity with the preliminary European Scleroderma Study Group (EScSG) activity index [12]. The Medsger scale of disease damage was used, with the exception that the joint/tendon and muscular item was not performed [13]. Organ involvement was defined as: suspected pulmonary hypertension $(\mathrm{sPH})$ : tricuspidalis $\mathrm{V}$ - $\max >2.9 \mathrm{~m} / \mathrm{s}$ on Doppler ultrasound. Pulmonary fibrosis: signs of fibrosis on $\mathrm{X}$-ray or high-resolution computed tomography (HRCT). HRCT was performed in $90 \%$ of the patients. Myositis: muscular weakness and elevated creatine kinase and signs of inflammation on magnetic resonance imaging (MRI), electromyography (EMG) or muscular biopsy. Arthritis: swollen joints on examination or arthritis documented in the journals. Kidney involvement: a history of scleroderma renal crisis or $>1$ on the Medsger scale for kidney damage [13].

Ischemic arterial events were defined as:

1. Ischemic heart disease (IHD): myocardial infarction (confirmed by electrocardiography and a reversible rise in plasma creatine kinase, muscle and brain fraction (CK-MB) or troponin $\mathrm{T}$ ) or angina pectoris (confirmed by an exercise stress test).

2. Ischemic cerebrovascular disease (ICVD): cerebral infarction (confirmed by computed tomography) or transitory ischemic attacks (TIA, defined as transient focal symptoms from the brain or retina with a maximum duration of 24 hours).

3. Ischemic peripheral vascular disease (IPVD): intermittent claudication + ankle-brachial index $(\mathrm{ABI})<0.9$ or peripheral arterial thrombosis/embolus (confirmed by angiogram or Doppler flow studies).

4. Any ischemic arterial event that includes 1 to 3 above

\section{Measures of atherosclerosis}

The left and right common carotid arteries and bifurcation areas were scanned for presence of plaque and images for IMT measurements were received using a duplex scanner (Siemens Acuson Sequoia, Mountain View, CA, USA) with a 7.0 $\mathrm{MHz}$ linear array transducer. Scans were digitalized for offline analysis. The subject's head was tilted to get the picture of the common carotid artery (CCA) just proximal to the bulb placed horizontally across the screen. Pictures were frozen synchronously with the $\mathrm{R}$ wave on the electrocardiogram. The IMT was defined as the distance between the leading edges of the luminal echo and the media/adventitia echo [14]. The IMT was calculated as the intima-media area divided by the measured length $(10 \mathrm{~mm})$ on one scan. Plaques were defined as a local increase in wall thickness of $>1 \mathrm{~mm}$ and $100 \%$ increase in wall thickness 
compared to the adjacent wall. A technician recorded all measurements and a single experienced reader (KJU) interpreted the registrations without knowledge of patient/control status or other test results.

To obtain the ABI, the patients were placed in a supine position. The highest systolic pressure of the tibialis posterior or dorsalis pedis for each foot were divided by the highest brachial systolic pressure to obtain an ankle-brachial pressure ratio.

\section{Laboratory analyses}

Antinuclear antibodies (ANA) were analyzed by immunofluorescence (IFL) on sections of rat liver and HEp-2 cells (Immunoconcepts, Sacramento, CA, USA). Anticentromere antibodies (ACA) and antitopoisomerase 1 antibodies (ATA) were analyzed by the BioPlex 2200 ANA screen system (Bio-Rad, Hercules, CA, USA). High-sensitivity C-reactive protein (hsCRP), $\alpha-1$ antitrypsin, orosomucoid and fibrinogen were measured using BN ProSpec System (Dade Behring, Deerfield, IL, USA). Intercellular adhesion molecule 1(ICAM-1), vascular cell adhesion molecule 1(VCAM-1), interleukin 6 (IL-6) and vascular endothelial growth factor (VEGF) were analyzed by sandwich ELISA kits (DY720, DY206, DY137 and DY293B, R \& D Systems, Minneapolis, MN, USA). Cutoff values were $15 \mathrm{pg} / \mathrm{mL}$ for ICAM-1, VCAM-1 and VEGF and $6 \mathrm{pg} / \mathrm{mL}$ for IL-6.

Cystatin C (reagent: 1014, Gentian, Moss, Norway) was analyzed on an Architect Ci8200 ${ }^{\mathrm{TM}}$ analyzer (Abbott, Abbot Park, IL, USA). The total analytical imprecision of the cystatin $\mathrm{C}$ method was $1.1 \%$ at $1.25 \mathrm{mg} / \mathrm{L}$ and $1.4 \%$ at $5.45 \mathrm{mg} / \mathrm{L}$. The equation used for calculating glomerular filtration rate (GFR) in $\mathrm{mL} / \mathrm{min} / 1.73 \mathrm{~m}^{2}$ from the cystatin $\mathrm{C}$ results in $\mathrm{mg} / \mathrm{mL}$ was $\mathrm{y}=79.901 \mathrm{x}^{-1.4389}[15]$.

von Willebrand factor (vWF) was measured by sandwich ELISA (Dako, Glostrup, Denmark) [16].

\section{Statistical methods}

Characteristics were summarized for all patients and controls. Skewed continuous variables were log transformed to obtain a normal distribution, if possible. Groups were compared using ANOVA, Mann-Whitney $U$ test and $X^{2}$ test as needed. Odds ratio (OR) and $95 \%$ confidence intervals $(\mathrm{CI})$ were calculated from $2 \times 2$ contingency tables or from nominal logistic regression models. For continuous variables, we used standard least squares linear regression to calculate standardized regression coefficients $(\beta)$ and $P$ values. Variables were sorted into functional groups (traditional risk factors, and so on. see Table 1). After age adjustment, the variables within each group, which were representative and most significantly, as determined by lowest $P$ value, associated with plaque occurrence were entered into a multivariable-adjusted model. Due to limited number of plaques, we restricted the number of variables to six. Calculations were done using JMP software
(SAS Institute, Cary, NC, USA). A $P$ value $<0.05$ was considered statistically significant.

\section{Results \\ Basic characteristics}

At inclusion patients with SSc had lower body mass index, lower diastolic blood pressure, but higher triglycerides and biomarkers of systemic inflammation/ endothelial activation as compared to controls. Baseline characteristics and comparisons between patients and controls are given in Table 1.

\section{Occurrence of ischemic arterial events and measures of atherosclerosis}

Ischemic arterial events were more common in patients than in controls (Table 2), due to more prevalent IHD and IPVD, while ICVD did not differ between groups (events are tabulated in detail, see Additional file 1,Table 1). Of participants with IHD, seven patients and three controls were diagnosed with myocardial infarction. The remaining IHD subjects had angina pectoris verified with an exercise test, of these two patients and one control had undergone an angiogram, all with normal cardiac vessels. Five patients and one control had had multiple events.

The majority of the IPVD patients (78\%) in our study had severe macrovasculopathy requiring surgical intervention. One SSc patient and the only control had IPVD based on $\mathrm{ABI}<0.9$ together with typical symptoms of claudication (see Additional file 1, Table 1).

Plaque occurrence, IMT and ABI did not differ between patients and controls (Table 2). Six patients and two controls had an ABI below 0.9 and one patient and one control had an ABI higher than 1.4.

\section{Risk factors for ischemic arterial events}

As expected, all ischemic arterial events were positively associated with age. We therefore adjusted all further calculations for age. All variables presented in Table 1 were investigated for associations with ischemic arterial events. All variables, which after age adjustment remained associated with at least one of the respective cardiovascular outcomes (any event, IHD or IPVD), are presented in Table 3. Age, kidney involvement, cystatin $C$ estimated (e)GFR were associated with any ischemic arterial event and with IHD. ACA+ and skin score were associated with any ischemic arterial event and IPVD. Interestingly, patients with ATA had less total events and less IHD. IHD was also associated with endothelial biomarkers. Due to few events, we were not able to perform further multivariable calculations.

\section{Risk factors for atherosclerosis}

The investigated measures of atherosclerosis were all positively associated with age. Thus, all further calculations 
Table 1 Characteristics of systemic sclerosis patients and controls at inclusion.

\begin{tabular}{|c|c|c|c|}
\hline & Patients $(n=111)$ & Controls $(n=105)$ & $P$ value \\
\hline Age, years & $61.8 \pm 12.5$ & $61.5 \pm 12.3$ & ns \\
\hline Gender female \% (n) & $81(90)$ & $86(90)$ & ns \\
\hline \multicolumn{4}{|l|}{ Disease characteristics } \\
\hline Disease duration (years) & $9.4(5.6-17.4)$ & - & - \\
\hline $\begin{array}{l}\text { Diffuse cutaneous \% (n) } \\
\text { Limited cutaneous \% (n) }\end{array}$ & $\begin{array}{l}22(24) \\
78(87)\end{array}$ & $\begin{array}{l}- \\
-\end{array}$ & - \\
\hline Pulmonary fibrosis \% (n) & $46(51)$ & - & - \\
\hline Suspected pulmonary hypertension \% (n) & $15(17)$ & 0 & - \\
\hline Raynaud \% (n) & $95(105)$ & $11(12)$ & - \\
\hline Digital ulcers ever \% (n) & $39(43)$ & 0 & - \\
\hline Calcinosis \% (n) & $27(30)$ & 0 & - \\
\hline Myositis \% (n) & $9(10)$ & 0 & - \\
\hline Arthritis \% (n) & $29(32)$ & $4(4)$ & - \\
\hline Kidney involvement \% (n) & $7(8)$ & 0 & - \\
\hline Skin score & $6(3-10)$ & 0 & - \\
\hline Disease activity & $0.5(0-2)$ & - & - \\
\hline Disease severity & $5(3-6)$ & - & - \\
\hline $\begin{array}{l}\text { Autoantibodies } \\
\text { Anticentromere (ACA) \% (n) } \\
\text { Antitopoisomerase } 1 \text { (ATA) \% (n) } \\
\text { Antinuclear (ANA) neg \% (n) }\end{array}$ & $\begin{array}{l}32(35) \\
23(25) \\
7(8)\end{array}$ & $\begin{array}{l}- \\
- \\
-\end{array}$ & \\
\hline \multicolumn{4}{|l|}{ Traditional cardiovascular risk factors } \\
\hline Body mass index $\left(\mathrm{kg} / \mathrm{m}^{2}\right)$ & $24.2 \pm 3.80$ & $26.0 \pm 3.7$ & 0.0005 \\
\hline Waist-hip ratio & $0.83 \pm 0.09$ & $0.84 \pm 0.08$ & ns \\
\hline $\begin{array}{l}\text { Ever smoked \% (n) } \\
\text { Current smoker \% (n) }\end{array}$ & $\begin{array}{l}53(59) \\
11(12)\end{array}$ & $\begin{array}{l}44(46) \\
7(7)\end{array}$ & $\begin{array}{l}\text { ns } \\
\text { ns }\end{array}$ \\
\hline $\begin{array}{l}\text { Systolic BP (mmHg) } \\
\text { Diastolic BP (mmHg) } \\
\text { Hypertension \% (n) }\end{array}$ & $\begin{array}{l}123.18 \pm 17.94 \\
71.63 \pm 10.65 \\
30(33)\end{array}$ & $\begin{array}{l}124.09 \pm 18.59 \\
74.5 \pm 9.49 \\
20(21)\end{array}$ & $\begin{array}{l}\text { ns } \\
0.04 \\
\text { ns }\end{array}$ \\
\hline $\begin{array}{l}\text { P-glucose }(\mathrm{mmol} / \mathrm{l}) \\
\text { Diabetes \% (n) }\end{array}$ & $\begin{array}{l}5.45 \pm 1.17 \\
6(7)\end{array}$ & $\begin{array}{l}5.43 \pm 1.34 \\
7(7)\end{array}$ & $\begin{array}{l}\text { ns } \\
\text { ns }\end{array}$ \\
\hline $\begin{array}{l}\text { Cholesterol (mmol/l) } \\
\text { LDL (mmol//) } \\
\text { HDL (mmol/l) } \\
\text { Triglycerides (mmol/l) }\end{array}$ & $\begin{array}{l}5.20 \pm 1.04 \\
3.32 \pm 0.93 \\
1.3(1.0-1.5) \\
0.99(0.76-1.5)\end{array}$ & $\begin{array}{l}5.24 \pm 1.15 \\
3.37 \pm 0.91 \\
1.4(1.2-1.7) \\
0.93(0.67-1.3)\end{array}$ & $\begin{array}{l}\text { ns } \\
\text { ns } \\
\text { ns (0.09) } \\
0.03\end{array}$ \\
\hline \multicolumn{4}{|l|}{ Inflammatory biomarkers } \\
\hline hsCRP (mg/l) & $2.2(1.0-4.3)$ & $1.75(0.76-3.2)$ & 0.05 \\
\hline Orosomucoid (g/l) & $0.86 \pm 0.23$ & $0.77 \pm 0.17$ & 0.0009 \\
\hline Alpha1antitrypsine (g/l) & $1.5(1.4-1.6)$ & $1.4(1.2-1.5)$ & $<0.0001$ \\
\hline Fibrinogen $(g / l)$ & $3.77(3.3-4.34)$ & $3.53(2.80-4.25)$ & 0.03 \\
\hline $\begin{array}{l}\text { Sedimentation rate }(\mathrm{mm}) \\
\text { Interleukin-6 }(\mathrm{pg} / \mathrm{ml})\end{array}$ & $\begin{array}{l}14(9-26) \\
29.9(21.4-40.9)\end{array}$ & $\begin{array}{l}10(7-16.5) \\
27.1(21.2-32.5)\end{array}$ & $\begin{array}{l}0.002 \\
\text { ns }(0.08)\end{array}$ \\
\hline \multicolumn{4}{|l|}{ Endothelial biomarkers } \\
\hline VCAM-1 (ng/l) & $698(546-807)$ & $531(431-719)$ & $<0.0001$ \\
\hline ICAM-1 (ng/l) & $376(314-472)$ & $330(254-450)$ & 0.002 \\
\hline VEGF (pg/ml) & $182(143-258)$ & $156(103-239)$ & 0.009 \\
\hline VWF (IU/ml) & $1.25(0.90-1.70)$ & $0.85(0.58-1.36)$ & $<0.0001$ \\
\hline \multicolumn{4}{|l|}{ Renal function } \\
\hline $\mathrm{eGFR}\left(\mathrm{mL} / \mathrm{min} / 1.73 \mathrm{~m}^{2}\right)$ & $74(50-116)$ & $104(89-126)$ & 0.01 \\
\hline
\end{tabular}

Distributions are given as $\%(n)$, median (interquartile range) or mean \pm standard deviation. BP, blood pressure; LDL, low-density lipoprotein; HDL, high-density lipoprotein; hsCRP, high-sensitivity C reactive protein; VCAM-1, vascular cell adhesion molecule 1; ICAM-1, intercellular adhesion molecule 1; VEGF, vascular endothelial growth factor; VWF, von Willebrand factor; eGFR, estimated glomerular filtration rate, based on cystatin C measurements. 
Table 2 Ischemic arterial events and surrogate measures of atherosclerosis in systemic sclerosis patients versus controls.

\begin{tabular}{|c|c|c|c|c|}
\hline & Patients $(n=111)$ & Controls $(n=105)$ & Odds ratio $(95 \% \mathrm{Cl})$ & $P$ value \\
\hline Any arterial event $\%(n)$ & $18(20)$ & $7(7)$ & $3.1(1.2-7.6)$ & 0.01 \\
\hline IHD \% (n) & $12(13)$ & $4(4)$ & $3.3(1.1-10.6)$ & 0.03 \\
\hline ICVD \% (n) & $3(4)$ & $3(3)$ & $0.9(0.2-4.7)$ & ns \\
\hline IPVD \% (n) & $8(9)$ & $1(1)$ & $9.2(1.1-73.7)$ & 0.02 \\
\hline \multirow[t]{2}{*}{ Plaques \% (n) } & $48(52)$ & $41(43)$ & $1.3(0.7-2.3)$ & ns \\
\hline & & & $\beta$-coefficient & \\
\hline IMT mm & $0.68 \pm 0.13$ & $0.68 \pm 0.13$ & -0.02 & ns \\
\hline$A B I$ & $1.13(1.1-1.2)$ & $1.12(1.1-1.2)$ & -0.08 & ns \\
\hline
\end{tabular}

Any arterial event refers to any ischemic arterial event, including IHD, ICVD and IPVD. IHD, ischemic heart disease; ICVD, ischemic cerebrovascular disease; IPVD, ischemic peripheral vascular disease; IMT, intima-media thickness; $A B I$, ankle-brachial index.

were age-adjusted. Each variable presented in Table 1 was investigated for association with plaque occurrence, IMT and ABI. All variables, which after age adjustment remained associated with at least one of the respective atherosclerosis outcomes (plaque, IMT or ABI), are presented in Table 4.

Plaque occurrence was associated with smoking, higher blood pressure, impaired kidney function, high levels of IL- 6 and VCAM-1 and with ACA+.

As expected, we noted that IMT was strongly associated with systolic blood pressure and with male gender. ABI was associated with disease activity, waist-hip ratio and smoking.

Several variables were associated with plaque occurrence and we included age and the variables with the lowest $P$ values in each 'functional group' in a multivariable-adjusted logistic regression. In this model only $\mathrm{ACA}+$ and high levels of IL- 6 remained convincingly associated with plaque occurrence, while the association with diastolic blood pressure was of borderline significance (Table 5).

\section{Subgroup analysis of ACA+ SSc patients}

Finally, due to the observed association between ACA+ and any ischemic arterial event and plaque occurrence, we stratified by ACA status and compared the groups with respect to all variables in Table 1 . There were $34 \mathrm{ACA}+$ patients and $77 \mathrm{ACA}$-patients. In the ACA+ group disease duration was longer $(P=0.04)$ and $\mathrm{dcSSc}$, pulmonary fibrosis, and ATA antibodies were less common $(P<0.05)$ compared with the ACA-group. Of traditional risk factors, waist-hip ratio, $\mathrm{P}$-glucose and triglycerides levels were lower in ACA+ patients $(P \leq 0.05)$. Levels of orosomucoid and ICAM-1 were also lower in the ACA+ group $(P \leq 0.05)$ (see Additional file 1, Table 2).

Occurrence of vascular events, measures of atherosclerosis and levels of endothelial markers in ACA+ and ACApatients (adjusted for age, sex and disease duration), and in $\mathrm{ACA}+$ patients and controls (adjusted for age and sex) are demonstrated in Table 6, Figure 1, Figure 2 and Figure 3.

A higher total of ischemic arterial events, IPVD, and more plaques were observed in $\mathrm{ACA}+$ patients as compared to both ACA-patients and controls.

Table 3 Variables associated with ischemic arterial events in systemic sclerosis patients after age adjustment.

\begin{tabular}{|c|c|c|c|c|c|c|}
\hline & \multicolumn{2}{|c|}{ Any event $(n=20)$} & \multicolumn{2}{|c|}{ IHD $(n=13)$} & \multicolumn{2}{|c|}{ IPVD $(n=9)$} \\
\hline & Odds ratio $(95 \% \mathrm{Cl})$ & $P$ value & Odds ratio $(95 \% \mathrm{Cl})$ & $P$ value & Odds ratio $(95 \% \mathrm{Cl})$ & $P$ value \\
\hline Age & $1.10(1.05-1.17)$ & $<0.0001$ & $1.06(1.01-1.13)$ & 0.02 & $1.13(1.05-1.26)$ & 0.0005 \\
\hline \multicolumn{7}{|c|}{ Associations after adjustment for age } \\
\hline Kidney disease & $8.8(1.5-55.8)$ & 0.01 & $6.6(1.12-36.15)$ & 0.04 & ND & 0.3 \\
\hline Skin score & $1.13(1.03-1.24)$ & 0.008 & $1.07(0.97-1.18)$ & 0.1 & $1.16(1.02-1.32)$ & 0.02 \\
\hline Disease severity & $1.29(1.05-1.62)$ & 0.02 & $1.11(0.88-1.39)$ & 0.4 & $1.15(0.85-1.55)$ & 0.3 \\
\hline $\mathrm{ACA}+$ & $3.61(1.21-11.3)$ & 0.02 & $1.9(0.55-6.45)$ & 0.2 & $6.8(1.37-45.3)$ & 0.02 \\
\hline ATA+ & $0.18(0.01-1.01)$ & 0.05 & $0.00003(0-0.6)$ & 0.01 & $0.83(0.04-5.67)$ & 0.9 \\
\hline VCAM-1 & $5.30(0.51-62.1)$ & 0.2 & $27.3(2.52-427.4)$ & 0.005 & $0.37(0.02-5.46)$ & 0.2 \\
\hline VEGF & $0.68(0.24-1.84)$ & 0.4 & $0.29(0.09-0.93)$ & 0.03 & $0.52(0.12-2.33)$ & 0.4 \\
\hline eGFR & $0.26(0.10-0.62)$ & 0.003 & $0.32(0.12-0.81)$ & 0.02 & $0.57(0.15-3.65)$ & 0.5 \\
\hline
\end{tabular}

$\mathrm{IHD}$, ischemic heart disease; IPVD, ischemic peripheral vascular disease; Cl, confidence interval; ACA, anticentromere antibody; +, positivity; ATA, antitopoisomerase 1 antibody; VCAM-1, vascular cell adhesion molecule 1; VEGF, vascular endothelial growth factor; eGFR, estimated glomerular filtration rate, based on cystatin $\mathrm{C}$ measurements. 
Table 4 Variables associated with measures of atherosclerosis in systemic sclerosis patients after age adjustment.

\begin{tabular}{|c|c|c|c|c|c|c|}
\hline & \multicolumn{2}{|c|}{ Plaques $(n=52)$} & \multicolumn{2}{|c|}{ IMT } & \multicolumn{2}{|c|}{$\mathrm{ABI}$} \\
\hline & $\begin{array}{l}\text { Odds ratio } \\
(95 \% \mathrm{Cl})\end{array}$ & $P$ value & $\beta$-coefficient & $P$ value & $\beta$-coefficient & $P$ value \\
\hline Age & $1.09(1.05-1.14)$ & $<0.0001$ & 0.66 & $<0.0001$ & -0.20 & 0.03 \\
\hline \multicolumn{7}{|c|}{ Associations after adjustment for age } \\
\hline Gender female & $0.39(0.12-1.18)$ & 0.1 & -0.19 & 0.0001 & -0.12 & 0.2 \\
\hline $\mathrm{ACA}+$ & $2.9(1.2-7.5)$ & 0.02 & -0.01 & 0.9 & -0.14 & 0.2 \\
\hline Digital ulcers & $2.6(1.1-6.6)$ & 0.03 & 0.10 & 0.2 & -0.09 & 0.4 \\
\hline Kidney disease & $11.5(1.7-232)$ & 0.03 & -0.05 & 0.5 & 0.05 & 0.6 \\
\hline Disease activity & $1.6(1.04-2.5)$ & 0.03 & 0.10 & 0.2 & -0.34 & 0.0004 \\
\hline Disease severity & $1.3(1.1-1.5)$ & 0.005 & 0.12 & 0.1 & 0.13 & 0.2 \\
\hline Waist-hip ratio & $2.6(0.01-645)$ & 0.7 & 0.09 & 0.2 & 0.19 & 0.04 \\
\hline Ever smoked & $2.5(1.05-6.7)$ & 0.04 & 0.10 & 0.2 & 0.24 & 0.01 \\
\hline Systolic BP & $1.0(1.0-1.1)$ & 0.02 & 0.28 & 0.0008 & -0.06 & 0.6 \\
\hline Diastolic BP & $1.1(1.0-1.1)$ & 0.008 & 0.13 & 0.1 & -0.02 & 0.9 \\
\hline Interleukin-6 & $3.5(1.5-9.3)$ & 0.003 & 0.12 & 0.1 & -0.13 & 0.2 \\
\hline VCAM-1 & $9.4(1.8-58.3)$ & 0.008 & -0.05 & 0.5 & 0.03 & 0.8 \\
\hline ICAM-1 & $0.32(0.05-1.98)$ & 0.2 & 0.16 & 0.04 & -0.12 & 0.2 \\
\hline eGFR & $0.4(0.2-0.99)$ & 0.04 & 0.11 & 0.2 & -0.04 & 0.7 \\
\hline
\end{tabular}

IMT, intima-media thickness; $\mathrm{ABI}$, ankle-brachial index; $\mathrm{Cl}$, confidence interval; $\mathrm{ACA}$, anticentromere antibodies; +, positivity; BP, blood pressure; VCAM-1, vascular cell adhesion molecule 1; ICAM-1, intercellular adhesion molecule 1; eGFR, estimated glomerular filtration rate, based on cystatin C measurements.

\section{Discussion}

The first major finding in this population-based study is that ischemic arterial events, specifically IHD and IPVD, are more common in patients with SSc, while ICVD and measures of atherosclerosis did not differ on a group level as compared to population controls. Second, the $\mathrm{ACA}+\mathrm{SSc}$ subgroup was more affected with ischemic arterial events and with carotid plaques in comparison both to other SSc patients and to controls.

Table 5 Multivariable adjusted model for occurrence of carotid plaques.

\begin{tabular}{lll}
\hline & \multicolumn{1}{c}{ Plaques } \\
\hline $\begin{array}{l}\text { Functional groups } \\
\text { and included variables }\end{array}$ & $\begin{array}{l}\text { Odds ratio } \\
(95 \% \mathrm{Cl})\end{array}$ & P value \\
\hline Age & $\mathbf{1 . 1}(\mathbf{1 . 0 3 - 1 . 1 6 )}$ & $\mathbf{0 . 0 0 3}$ \\
Disease characteristics & $\mathbf{4 . 0}(\mathbf{1 . 2 6 - 1 4 . 1 )}$ & $\mathbf{0 . 0 2}$ \\
ACA+ & & \\
Traditional risk factors & $\mathbf{1 . 1}(\mathbf{1 . 0 1 - 1 . 1 1 )}$ & $\mathbf{0 . 0 4}$ \\
$\begin{array}{l}\text { Diastolic blood pressure }(\mathrm{mmHg}) \\
\text { Inflammatory biomarkers }\end{array}$ & $\mathbf{3 . 8}(\mathbf{1 . 3 - 1 3 . 3 )}$ & $\mathbf{0 . 0 1}$ \\
$\begin{array}{l}\text { IL-6 (pg/ml) } \\
\text { Endothelial biomarkers }\end{array}$ & $1.5(0.15-14.7)$ & 0.7 \\
$\begin{array}{l}\text { VCAM-1 (ng/ml) } \\
\text { Kidney function test } \\
\left.\text { eGFR (mL/min/1.73 } \mathrm{m}^{2}\right)\end{array}$ & $0.3(0.04-1.07)$ & 0.07 \\
\hline
\end{tabular}

$\mathrm{Cl}$, confidence interval; $\mathrm{ACA}$, anticentromere antibodies; +, positivity; IL, interleukin; VCAM-1, vascular cell adhesion molecule 1; eGFR, estimated glomerular filtration rate, based on cystatin $\mathrm{C}$ measurements.
The observed high prevalence of IPVD in patients with SSc highlights an important clinical problem recently also reported by Man et al. [17]. Youssef et al. [18] found an even higher prevalence of IPVD in females with lcSSc compared with controls (58\% vs.10\%). More claudication, as a sign of IPVD, was also reported in SSc patients by Veale and collaborators [19].

Despite the higher prevalence of IPVD, SSc patients did not, as a group, have lower ABI than controls. This is in line with three previous studies [20-22], but contrasts with Ho et al. [23]. In our study, ACA+ patients had more IPVD compared to both ACA-patients and controls and there was also a trend toward lower $\mathrm{ABI}$ in the ACA+ group. Wan et al. examined ABI in 119 SSc patients and found no difference between patients with lcSSc and dcSSc, but interestingly ACA+ seemed to prevail among patients with symptomatic ischemic disease [24]. Previous studies have identified ACA+ as a predictor for severe digital loss $[25,26]$. Thus, in addition to microvascular disease, the large arteries of the extremities seem to contribute significantly to the severe distal ischemic damage seen in many SSc patients, especially in the ACA+ subgroup.

We report a three-fold increased occurrence of IHD in SSc patients and even higher figures in the ACA+ subgroup. This is in line with the recently reported incidence of myocardial infarction [17] and self-reported IHD [27], both of which were two-fold enhanced in SSc patients versus the general population. Older autopsy studies described that myocardial infarctions were 
Table 6 Ischemic arterial events and surrogate measures of atherosclerosis in ACA+ patients versus ACA-patients and controls.

\begin{tabular}{|c|c|c|c|c|c|c|c|}
\hline & \multicolumn{3}{|c|}{ Occurrence of events and atherosclerosis } & \multicolumn{2}{|c|}{$A C A+$ vs. ACA- } & \multicolumn{2}{|c|}{ ACA+ vs. controls } \\
\hline & $\begin{array}{l}\text { ACA+ } \\
(n=34)\end{array}$ & $\begin{array}{l}\text { ACA- } \\
(n=77)\end{array}$ & $\begin{array}{l}\text { Controls } \\
(n=105)\end{array}$ & $\begin{array}{l}\text { Odds ratio** } \\
(95 \% \mathrm{Cl})\end{array}$ & $P$ value** & $\begin{array}{l}\text { Odds ratio* } \\
(95 \% \mathrm{Cl})\end{array}$ & $P$ value* \\
\hline Any arterial event \% (n) & $32(11)$ & $11(9)$ & $7(7)$ & $5.1(1.57-18.6)$ & 0.01 & $8.5(2.6-31.7)$ & 0.0003 \\
\hline IHD \% (n) & $18(6)$ & $9(7)$ & $4(4)$ & $2.6(0.7-10.0)$ & 0.2 & $4.8(1.2-20.7)$ & 0.02 \\
\hline ICVD \% (n) & $6(2)$ & $3(2)$ & $3(3)$ & $4.0(0.4-49.0)$ & 0.2 & $2.0(0.2-13.9)$ & 0.6 \\
\hline IPVD \% (n) & $18(6)$ & $4(3)$ & $1(1)$ & $9.1(1.6-79.1)$ & 0.01 & $70.1(6.5-2524)$ & $<0.0001$ \\
\hline \multirow[t]{2}{*}{ Plaque \% (n) } & $65(22)$ & $39(30)$ & $41(43)$ & $3.1(1.2-8.5)$ & 0.02 & $2.8(1.1-7.6)$ & 0.04 \\
\hline & & & & $\beta$-coefficient & & $\beta$-coefficient & \\
\hline IMT mm & $0.69 \pm 0.13$ & $0.68 \pm 0.13$ & $0.68 \pm 0.13$ & 0.03 & 0.7 & 0.01 & 0.6 \\
\hline$A B \mid$ & $1.1(1.03-1.2)$ & $1.1(1.17-1.2)$ & $1.1(1.07-1.2)$ & -0.12 & 0.08 & -0.14 & 0.07 \\
\hline
\end{tabular}

Distributions are given as \%, median (interquartile range) or mean \pm standard deviation. **adjusted for age, sex and disease duration; *adjusted for age and sex. ACA, anticentromere antibodies; +, positivity; -, negativity; Cl, confidence interval; IHD, ischemic heart disease; ICVD, ischemic cerebrovascular disease; IPVD, ischemic peripheral vascular disease; IMT, intima-media thickness; ABI, ankle-brachial index.

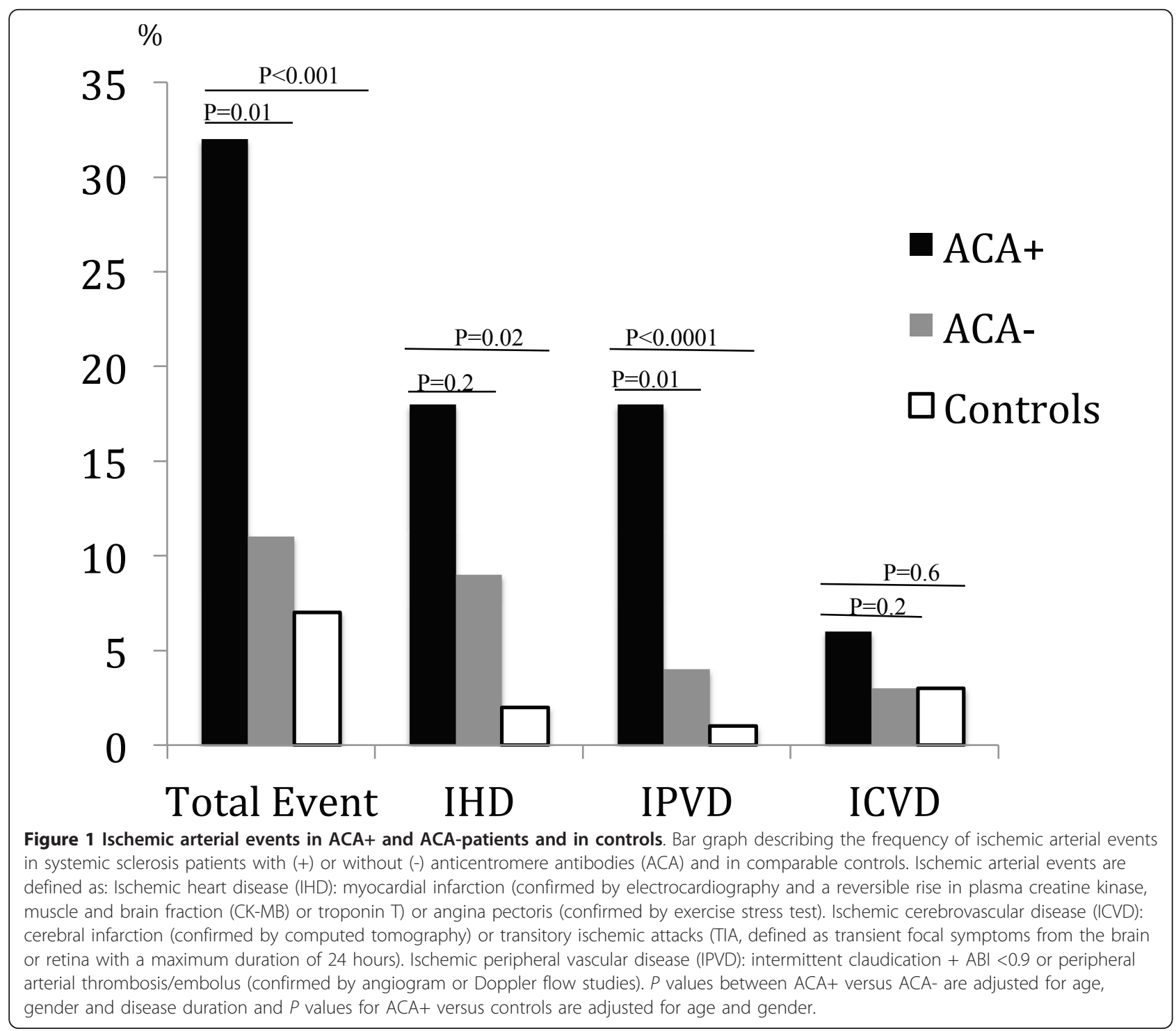




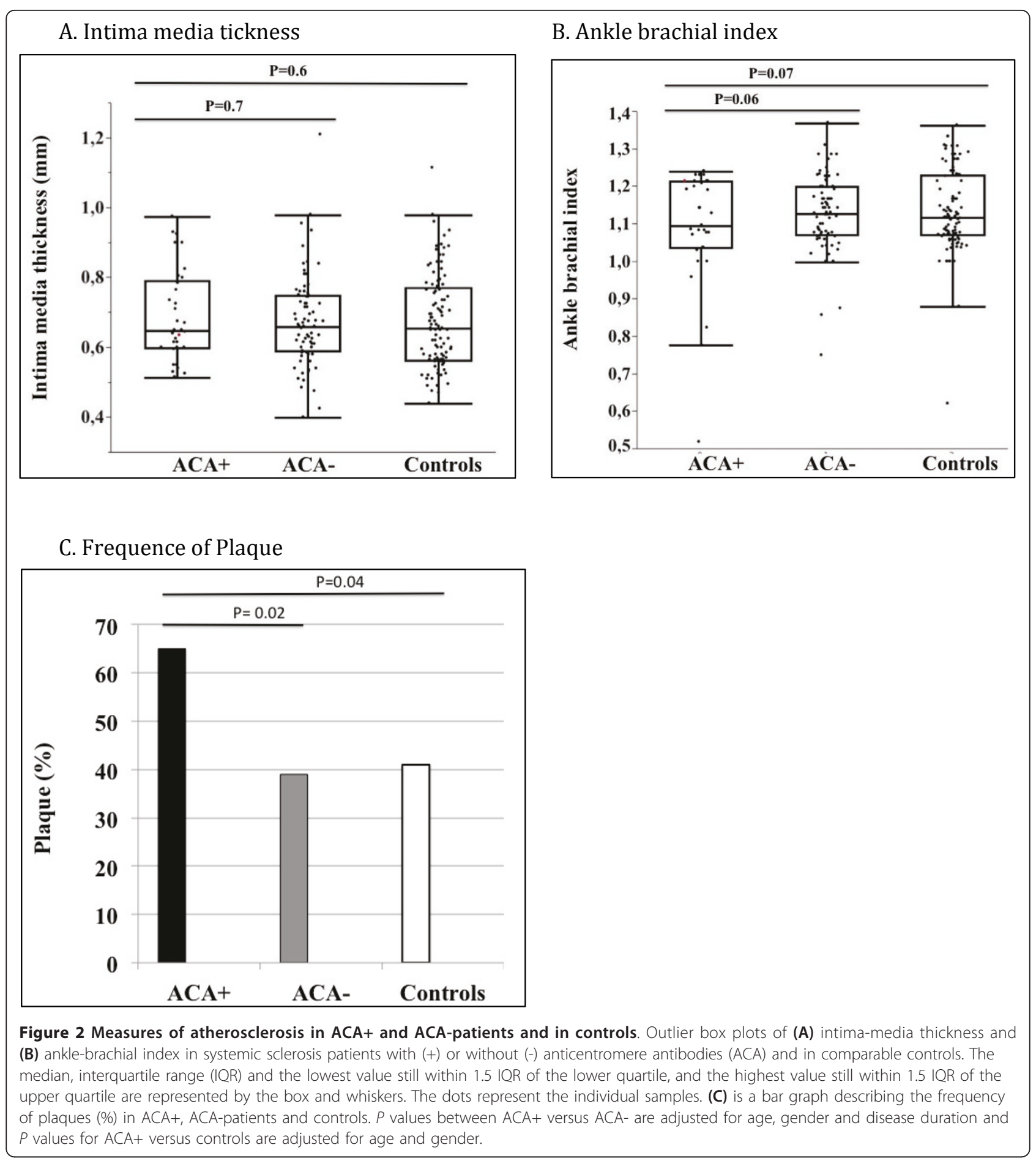

common in SSc patients, despite normal coronary arteries [28,29]. Akram et al. evaluated 179 angiograms from SSc patients but did not find an increased prevalence of coronary atherosclerosis [30] and normal angiograms were more common than expected among 11 SSc patients with myocardial infarction [31]. These studies suggest that vasospasm rather than atherosclerosis is a major pathogenic mechanism behind SSc-related heart disease. On the other hand, MRI studies have found that calcification of cardiac vessels are common in SSc [32]. The inconsistent results of previous work may partly be explained by our observation that atherosclerotic plaque 


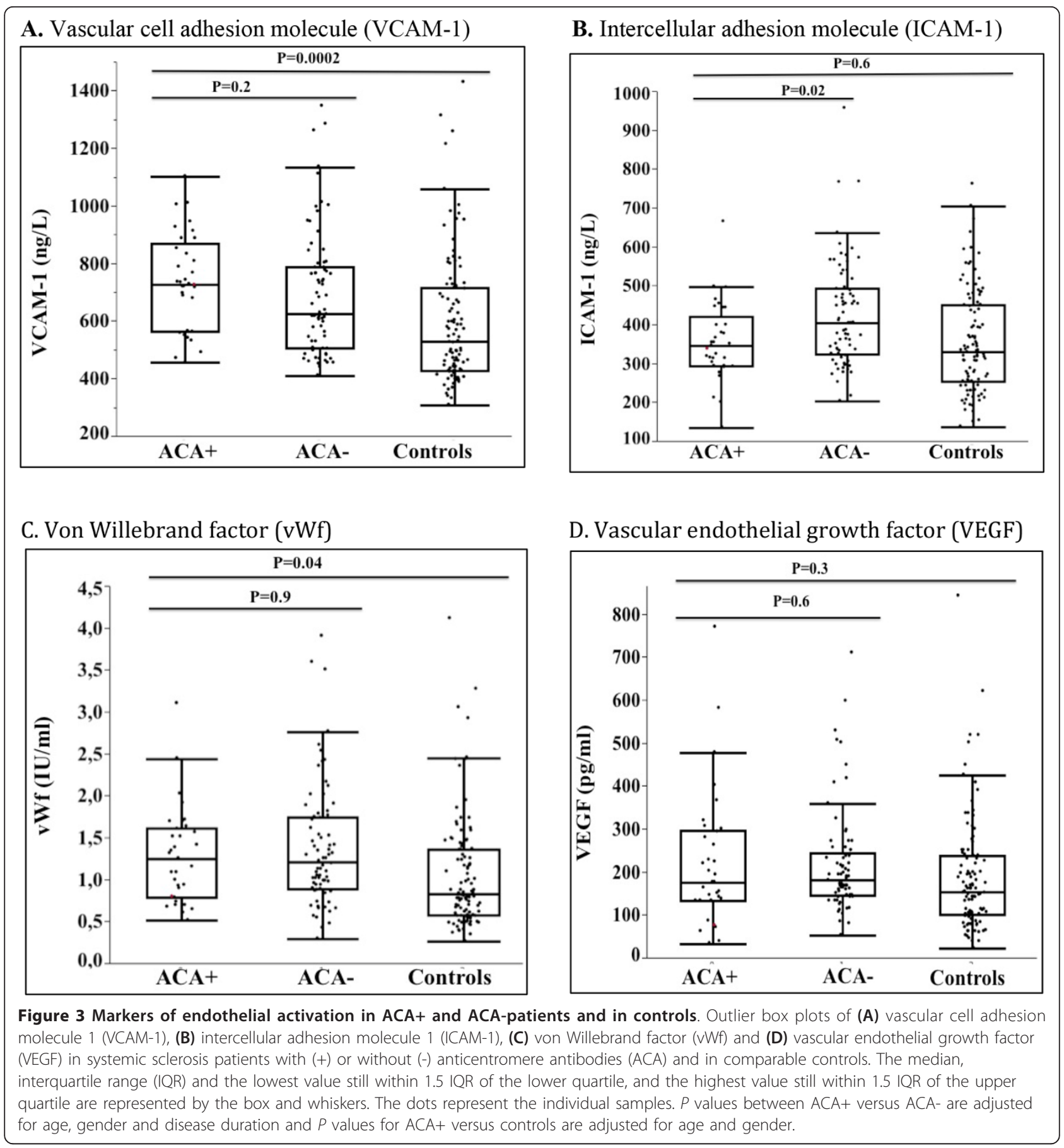

occurrence is selectively enhanced in the ACA+ subgroup of SSc patients.

In our study, impaired kidney function was highly associated with IHD, a finding that is supported by Derk et al., who reported that the majority of SSc patients with IHD had renal failure [30].

Cerebrovascular disease was, in accordance with Youssef et al., equally common in SSc patients and controls
[18]. However, recently Man et al. reported enhanced incidence of stroke in a large epidemiological study [17].

On a group level, there was no difference between patients and controls concerning atherosclerosis, measured as plaques occurrence, IMT or ABI. Our study population was fairly old and the plaque frequency was high in both patients and controls. Previous studies are smaller and the majority measured only IMT. Some 
report, in agreement with us, similar IMT in patients and controls [5,33-37], others found thicker IMT in SSc patients $[20,38-40]$. Only three studies examined the frequency of plaques, but their definitions of plaque differ $[20,23,41]$. We had no exclusion criteria, while some studies excluded SSc patients with manifest cardiovascular disease (CVD) $[4,20,35,36]$. Furthermore, the selection of comparators is important. The healthy controls in previous studies are likely to have less atherosclerosis than our population-based controls. Methods, definition and selection procedures of both patients and controls are likely to contribute to the heterogeneity of previous studies, reviewed in a recent meta-analysis [7].

Generally, levels of endothelial and inflammatory biomarkers were higher in patients compared to controls, demonstrating that SSc is a low-grade inflammatory disease. Of investigated inflammatory biomarkers, IL-6 remained independently associated with plaques. For SSc this is a new observation but IL- 6 has been identified as a risk factor for subclinical coronary atherosclerosis in RA [42], and it has also been linked to poor prognosis in patients with IHD from the general population [43].

VCAM-1 was associated with both IHD and plaques, though the latter association did not remain in multivariable analysis. In a previous study VCAM was associated with arterial stiffness in patients with SSc [44]. We reported recently in a prospective study that VCAM-1 levels predicted cardiovascular mortality in SLE [45]. The present observation adds further support for a pivotal role of the endothelium in autoimmune vascular disease.

Plaques were more common in ACA+ SSc patients, compared both to ACA-patients and controls. This difference remained after adjustment for disease duration, gender and age.

It is of note that, despite the enhanced occurrence of ischemic arterial events and plaques, several traditional CVD risk factors (waist-hip ratio, plasma glucose and triglycerides) had a less 'atherogenic' profile in the ACA+ as compared to the ACA-patients. Another important observation is that ischemic events were rare in the ATA+ group. These patients are part of the ACA-group, which consists of patients with different autoantibody profiles. In previous studies, ACA+ patients had a different disease presentation with more localized skin involvement, calcinosis [46], digital loss [26] and also a different genetic background [47]. Cheng et al. previously noted that the carotid wall of patients with SSc was stiffer than that of controls, and in subgroup analysis stiffness was more pronounced in dcSSc than in lcSSc [33]. Together these results imply that the antibody profiles and associated disease subsets contribute to vascular vulnerability in SSc.

To date this is the largest epidemiologically based study investigating both ischemic macrovascular disease and atherosclerosis in patients with SSc and in comparable population-based controls. Nevertheless, we are underpowered for more detailed subgroup analysis and for multivariable analysis of events. The cross-sectional design is a weakness restricting our investigation to survivors of vascular events. Case definitions in the national registries are based on ICD codes and differ from the definitions used in this study. We were thus restricted to compare event rates to our own controls, and could not reliably use the general population/national registries.

\section{Conclusions}

We report increased prevalence of ischemic arterial events, affecting preferentially the heart and peripheral arteries in SSc patients, especially in ACA+ patients, where also atherosclerosis was enhanced. Our results demonstrate the importance to perform detailed clinical descriptive studies, including subgroup analysis of established diagnostic entities. The importance to investigate both the macro- and microvasculature in SSc is underscored. In particular, ACA+ patients should be monitored closely and modifiable cardiovascular risk factors treated at an early stage to avoid ischemic complications such as amputations and myocardial infarctions.

\section{Additional material}

Additional file 1: Supplementary table Table 1. Specification of macrovascular events in SSc patients and controls Table 2. Characteristics of ACA+ versus ACA-SSC patients.

\section{Abbreviations}

ABl: ankle-brachial index; ACA: anticentromere antibodies; ACR: American College of Rheumatology; ANA: antinuclear antibodies; ANOVA: analysis of variance; ATA: antitopoisomerase 1 antibodies; BP: blood pressure; CCA: common carotid artery; Cl: confidence interval; CK-MB: creatine kinase: muscle and brain fraction; CVD: cardiovascular disease; dcSSc: diffuse cutaneous systemic sclerosis; ELISA: enzyme-linked immunosorbent assay; EMG: electromyography; EScSG: European Scleroderma Study Group; GFR: glomerular filtration rate; HDL: high-density lipoprotein; HRCT: highresolution computed tomography: hsCRP: high-sensitivity $C$ reactive protein; ICAM-1: intercellular adhesion molecule 1; ICVD: ischemic cerebrovascular disease; IFL: immunofluorescence; IHD: ischemic heart disease; IL-6: interleukin 6; IMT: intima-media thickness; IPVD: ischemic peripheral vascular disease; ICSSc: limited cutaneous systemic sclerosis; LDL: low-density lipoprotein; MHz: megahertz; MRI: magnetic resonance imaging; OR: odds ratio; $\mathrm{PH}$ : pulmonary hypertension; RA: rheumatoid arthritis; SSA/SSB: Sjögren's syndrome antigen A and B; SSC: systemic sclerosis; SLE: systemic lupus erythematosus; TIA: transitory ischemic attacks; VCAM-1: vascular cell adhesion molecule 1; vWf: von Willebrand factor.

\section{Competing interests}

The authors declare that they have no competing interests.

\section{Authors' contributions}

AN designed the study, acquired, analyzed and interpreted the data and drafted the manuscript. KJU acquired and analyzed the data and drafted the manuscript. LB designed the study, acquired the data and drafted the manuscript. SP coordinated the study, acquired the data and drafted the manuscript. AL coordinated and acquired the laboratory data and drafted the manuscript. ES designed the study, analyzed and interpreted the data 
and drafted the manuscript. All authors reviewed and approved the final manuscript.

\section{Acknowledgements}

We thank Karin Vengemyr, Christa Liewendahl-Wigren, Eva Jemseby and Gull-Britt Almgren for management of patient cohorts and blood sampling, Göran Lindahl, Kristina Albertsson, Ylva Rydvald and Brigitte Dupré for identification of patients and Lars Klareskog for encouragement and support. The study was funded by the Swedish Heart-Lung Foundation, the Swedish Research Council (B0295701, ES), the Swedish Rheumatism Association (ES, LB), King Gustaf V's 80-year Foundation (ES), the Swedish Society of Medicine (ES), the Åke Wiberg Foundation (ES), the Clas Groschinsky Memory Foundation (ES), Karolinska Institutet Foundations (ES), ALF funding from Stockholm County Council and the Karolinska Institutet (ES, LB).

\section{Authors' details}

'Rheumatology Unit, Department of Medicine, Karolinska University Hospital, Solna, Karolinska Institutet, SE-171 76 Stockholm, Sweden. ${ }^{2}$ Department of Clinical Physiology, Södersjukhuset, Karolinska Institutet, SE-171 76 Stockholm, Sweden. ${ }^{3}$ Division of Nursing, Department of Neurobiology, Care Sciences and Society, Karolinska Institutet, SE-171 76 Stockholm, Sweden. ${ }^{4}$ Department of Clinical Chemistry and Pharmacology, Akademiska Hospital, SE-751 85 Uppsala, Sweden.

Received: 10 November 2012 Revised: 2 April 2013

Accepted: 14 August 2013 Published: 14 August 2013

\section{References}

1. Tyndall AJ, Bannert B, Vonk M, Airo P, Cozzi F, Carreira PE, Bancel DF, Allanore Y, Muller-Ladner U, Distler O, lannone F, Pellerito R, Pileckyte M, Miniati I, Ananieva L, Gurman AB, Damjanov N, Mueller A, Valentini G, Riemekasten G, Tikly M, Hummers L, Henriques MJ, Caramaschi P, Scheja A, Rozman B, Ton E, Kumanovics G, Coleiro B, Feierl E, et al: Causes and risk factors for death in systemic sclerosis: a study from the EULAR Scleroderma Trials and Research (EUSTAR) database. Ann Rheum Dis 2010, 69:1809-1815.

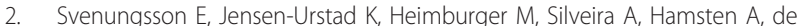
Faire U, Witztum JL, Frostegard J: Risk factors for cardiovascular disease in systemic lupus erythematosus. Circulation 2001, 104:1887-1893.

3. Bjornadal L, Brandt L, Klareskog L, Askling J: Impact of parental history on patients' cardiovascular mortality in rheumatoid arthritis. Ann Rheum Dis 2006, 65:741-745.

4. Tsifetaki N, Georgiadis AN, Alamanos Y, Fanis S, Argyropoulou Ml, Drosos AA: Subclinical atherosclerosis in scleroderma patients. Scand J Rheumatol 2010, 39:326-329.

5. Hettema ME, Zhang D, de Leeuw K, Stienstra Y, Smit AJ, Kallenberg CG, Bootsma $\mathrm{H}$ : Early atherosclerosis in systemic sclerosis and its relation to disease or traditional risk factors. Arthritis Res Ther 2008, 10:R49.

6. Nussinovitch U, Shoenfeld Y: Atherosclerosis and macrovascular involvement in systemic sclerosis: Myth or reality. Autoimmun Rev 2011, 10:259-266.

7. Au K, Singh MK, Bodukam V, Bae S, Maranian P, Ogawa R, Spiegel B, McMahon M, Hahn B, Khanna D: Atherosclerosis in systemic sclerosis: a systematic review and meta-analysis. Arthritis Rheum 2011, 63:2078-2090.

8. Walker UA, Tyndall A, Czirjak L, Denton C, Farge-Bancel D, Kowal-Bielecka O, Muller-Ladner U, Bocelli-Tyndall C, Matucci-Cerinic M: Clinical risk assessment of organ manifestations in systemic sclerosis: a report from the EULAR Scleroderma Trials And Research group database. Ann Rheum Dis 2007, 66:754-763.

9. Preliminary criteria for the classification of systemic sclerosis (scleroderma). Subcommittee for scleroderma criteria of the American Rheumatism Association Diagnostic and Therapeutic Criteria Committee. Arthritis Rheum 1980, 23:581-590.

10. LeRoy EC, Medsger TA Jr: Criteria for the classification of early systemic sclerosis. J Rheumatol 2001, 28:1573-1576.

11. Clements $P$, Lachenbruch $P$, Siebold J, White B, Weiner S, Martin R, Weinstein A, Weisman M, Mayes M, Collier D, Wigley F, Medsger T, Steen V, Moreland L, Dixon M, Massa M, Lally E, McCloskey D, Varga J, Ingenito F, Furst D: Inter and intraobserver variability of total skin thickness score (modified Rodnan TSS) in systemic sclerosis. J Rheumatol 1995, 22:1281-1285.
12. Valentini G, Silman AJ, Veale D: Assessment of disease activity. Clin Exp Rheumatol 2003, 21:S39-41

13. Medsger TA Jr, Bombardieri S, Czirjak L, Scorza R, Della Rossa A, Bencivelli W: Assessment of disease severity and prognosis. Clin Exp Rheumatol 2003, 21:S42-46.

14. Wikstrand J, Wendelhag I: Methodological considerations of ultrasound investigation of intima-media thickness and lumen diameter. J Intern Med 1994, 236:555-559.

15. Flodin M, Jonsson AS, Hansson LO, Danielsson LA, Larsson A: Evaluation of Gentian cystatin C reagent on Abbott Ci8200 and calculation of glomerular filtration rate expressed in $\mathrm{mL} / \mathrm{min} / 1.73 \mathrm{~m}(2)$ from the cystatin C values in mg/L. Scand I Clin Lab Invest 2007, 67:560-567.

16. Lethagen S, Carlson M, Hillarp A: A comparative in vitro evaluation of six von Willebrand factor concentrates. Haemophilia 2004, 10:243-249.

17. Man A, Zhu Y, Zhang Y, Dubreuil M, Rho YH, Peloquin C, Simms RW, Choi HK: The risk of cardiovascular disease in systemic sclerosis: a population-based cohort study. Ann Rheum Dis 2013, 72:1188-1193.

18. Youssef $P$, Brama T, Englert $H$, Bertouch J: Limited scleroderma is associated with increased prevalence of macrovascular disease. J Rheumatol 1995, 22:469-472.

19. Veale DJ, Collidge TA, Belch JJ: Increased prevalence of symptomatic macrovascular disease in systemic sclerosis. Ann Rheum Dis 1995, 54:853-855.

20. Bartoli F, Angotti C, Fatini C, Conforti ML, Guiducci S, Blagojevic J, Melchiorre D, Fiori G, Generini S, Damjanov N, Rednic S, Pignone A, Castellani S, Abbate R, Matucci Cerinic M: Angiotensin-converting enzyme I/D polymorphism and macrovascular disease in systemic sclerosis. Rheumatology (Oxford) 2007, 46:772-775.

21. Kaloudi O, Basta G, Perfetto F, Bartoli F, Del Rosso A, Miniati I, Conforti ML, Generini S, Guiducci S, Abbate R, Pignone A, Castellani S, Livi R, De Caterina R, Matucci-Cerinic M: Circulating levels of Nepsilon(carboxymethyl)lysine are increased in systemic sclerosis. Rheumatology (Oxford) 2007, 46:412-416.

22. Muro $Y$, Sugiura $K$, Morita $Y$, Tomita $Y$ : An evaluation of the efficacy of the toe brachial index measuring vascular involvement in systemic sclerosis and other connective tissue diseases. Clin Exp Rheumatol 2009, 27:26-31.

23. Ho M, Veale D, Eastmond C, Nuki G, Belch J: Macrovascular disease and systemic sclerosis. Ann Rheum Dis 2000, 59:39-43.

24. Wan MC, Moore T, Hollis S, Herrick AL: Ankle brachial pressure index in systemic sclerosis: influence of disease subtype and anticentromere antibody. Rheumatology (Oxford) 2001, 40:1102-1105.

25. Herrick AL, Heaney M, Hollis $\mathrm{S}$, Jayson Ml: Anticardiolipin, anticentromere and anti-Scl-70 antibodies in patients with systemic sclerosis and severe digital ischaemia. Ann Rheum Dis 1994, 53:540-542.

26. Wigley FM, Wise RA, Miller R, Needleman BW, Spence RJ: Anticentromere antibody as a predictor of digital ischemic loss in patients with systemic sclerosis. Arthritis Rheum 1992, 35:688-693.

27. Ngian GS, Sahhar J, Proudman SM, Stevens W, Wicks IP, Van Doornum S: Prevalence of coronary heart disease and cardiovascular risk factors in a national cross-sectional cohort study of systemic sclerosis. Ann Rheum Dis 2012, 71:980-1983.

28. Bulkley BH, Ridolfi RL, Salyer WR, Hutchins GM: Myocardial lesions of progressive systemic sclerosis. A cause of cardiac dysfunction. Circulation 1976, 53:483-490.

29. D'Angelo WA, Fries JF, Masi AT, Shulman LE: Pathologic observations in systemic sclerosis (scleroderma). A study of fifty-eight autopsy cases and fifty-eight matched controls. Am J Med 1969, 46:428-440.

30. Akram MR, Handler CE, Williams M, Carulli MT, Andron M, Black CM, Denton CP, Coghlan JG: Angiographically proven coronary artery disease in scleroderma. Rheumatology (Oxford) 2006, 45:1395-1398.

31. Derk CT, Jimenez SA: Acute myocardial infarction in systemic sclerosis patients: a case series. Clin Rheumatol 2007, 26:965-968.

32. Mok MY, Chiu SS, Lo Y, Mak HK, Wong WS, Khong PL, Lau CS: Coronary atherosclerosis using computed tomography coronary angiography in patients with systemic sclerosis. Scand I Rheumatol 2009, 38:381-385.

33. Cheng KS, Tiwari A, Boutin A, Denton CP, Black CM, Morris R, Hamilton $G$, Seifalian AM: Carotid and femoral arterial wall mechanics in scleroderma. Rheumatology (Oxford) 2003, 42:1299-1305.

34. Zakopoulos NA, Kotsis VT, Gialafos EJ, Papamichael CM, Pitiriga V, Mitsibounas DN, Mavrikakis ME: Systemic sclerosis is not associated with clinical or ambulatory blood pressure. Clin Exp Rheumatol 2003, 21:199-204. 
35. Szucs G, Timar O, Szekanecz Z, Der H, Kerekes G, Szamosi S, Shoenfeld Y, Szegedi G, Soltesz P: Endothelial dysfunction precedes atherosclerosis in systemic sclerosis-relevance for prevention of vascular complications. Rheumatology (Oxford) 2007, 46:759-762.

36. Roustit M, Simmons GH, Baguet JP, Carpentier P, Cracowski JL: Discrepancy between simultaneous digital skin microvascular and brachial artery macrovascular post-occlusive hyperemia in systemic sclerosis. I Rheumatol 2008, 35:1576-1583.

37. Liu J, Zhang Y, Cao TS, Duan YY, Yuan LJ, Yang YL, Li Y, Yao L: Preferential macrovasculopathy in systemic sclerosis detected by regional pulse wave velocity from wave intensity analysis: comparisons of local and regional arterial stiffness parameters in cases and controls. Arthritis Care Res (Hoboken) 2011, 63:579-587.

38. Lekakis J, Mavrikakis M, Papamichael C, Papazoglou S, Economou O, Scotiniotis I, Stamatelopoulos K, Vemmos C, Stamatelopoulos S, Moulopoulos S: Short-term estrogen administration improves abnormal endothelial function in women with systemic sclerosis and Raynaud's phenomenon. Am Heart J 1998, 136:905-912.

39. Bartoli F, Blagojevic J, Bacci M, Fiori G, Tempestini A, Conforti ML, Guiducci S, Miniati I, Di Chicco M, Del Rosso A, Perfetto F, Castellani S, Pignone A, Cerinic MM: Flow-mediated vasodilation and carotid intimamedia thickness in systemic sclerosis. Ann N Y Acad Sci 2007, 1108:283-290.

40. Sherer Y, Cerinic MM, Bartoli F, Blagojevic J, Conforti ML, Gilburd B, Ehrenfeld M, Shoenfeld Y: Early atherosclerosis and autoantibodies to heat-shock proteins and oxidized LDL in systemic sclerosis. Ann N Y Acad Sci 2007, 1108:259-267.

41. Vettori S, Maresca L, Cuomo G, Abbadessa S, Leonardo G, Valentini G: Clinical and subclinical atherosclerosis in systemic sclerosis: consequences of previous corticosteroid treatment. Scand J Rheumatol 2010, 39:485-489.

42. Rho YH, Chung CP, Oeser A, Solus J, Asanuma Y, Sokka T, Pincus T, Raggi P, Gebretsadik T, Shintani A, Stein CM: Inflammatory mediators and premature coronary atherosclerosis in rheumatoid arthritis. Arthritis Rheum 2009, 61:1580-1585.

43. Danesh J, Kaptoge S, Mann AG, Sarwar N, Wood A, Angleman SB, Wensley F, Higgins JP, Lennon L, Eiriksdottir G, Rumley A, Whincup PH, Lowe GD, Gudnason V: Long-term interleukin-6 levels and subsequent risk of coronary heart disease: two new prospective studies and a systematic review. PLoS Med 2008, 5:e78.

44. Andersen GN, Mincheva-Nilsson L, Kazzam E, Nyberg G, Klintland N, Petersson AS, Rantapaa-Dahlqvist S, Waldenstrom A, Caidahl K: Assessment of vascular function in systemic sclerosis: indications of the development of nitrate tolerance as a result of enhanced endothelial nitric oxide production. Arthritis Rheum 2002, 46:1324-1332.

45. Gustafsson J, Simard JF, Gunnarsson I, Elvin K, Lundberg IE, Hansson LO, Larsson A, Svenungsson E: Risk factors for cardiovascular mortality in patients with systemic lupus erythematosus, a prospective cohort study. Arthritis Res Ther 2012, 14:R46.

46. Steen VD, Powell DL, Medsger TA Jr: Clinical correlations and prognosis based on serum autoantibodies in patients with systemic sclerosis. Arthritis Rheum 1988, 31:196-203.

47. Beretta L, Rueda B, Marchini M, Santaniello A, Simeon CP, Fonollosa V, Caronni M, Rios-Fernandez R, Carreira P, Rodriguez-Rodriguez L, Moreno A, Lopez-Nevot MA, Escalera A, Gonzalez-Escribano MF, Martin J, Scorza R: Analysis of Class II human leucocyte antigens in Italian and Spanish systemic sclerosis. Rheumatology (Oxford) 2012, 51:52-59.

doi:10.1186/ar4267

Cite this article as: Nordin et al:: Ischemic arterial events and atherosclerosis in patients with systemic sclerosis: a population-based case-control study. Arthritis Research \& Therapy 2013 15:R87.

\section{Submit your next manuscript to BioMed Central and take full advantage of:}

- Convenient online submission

- Thorough peer review

- No space constraints or color figure charges

- Immediate publication on acceptance

- Inclusion in PubMed, CAS, Scopus and Google Scholar

- Research which is freely available for redistribution

Submit your manuscript at www.biomedcentral.com/submit
Biomed Central 